\title{
Faktor Faktor Yang Berhubungan Dengan Kejadian Anemia Pada Ibu Hamil Di Wilayah Kerja UPTD Puskesmas Siak Hulu I Dan III Tahun 2018
}

\author{
Elvanita1', Buchari Lapau², Oktavia Dewi² \\ 1Prodi Magister Kesehatan M asyarakat \\ ${ }^{2} \mathrm{STIK}$ es Hang Tuah Pekanbaru \\ Email : elvanita_rahman@yahoo.com
}

\begin{abstract}
Anemia in pregnancy is a condition where hemoglobin $(\mathrm{Hb})$ levels in pregnant women in trimester I and III $<11$ grams\%, while in trimester II Hb levels $<10.5 \%$. Normal hemoglobin levels in pregnant women $>11$ grams\%. UPTD Siak Hulu Health Centers I and III were the health centers that had the highest anemia cases in kampar regency in two consecutive years, namely $14.60 \%$ and $67.68 \%$ in 2016, while in 2017 were $63.63 \%$ and $85.83 \%$. This study aims to determine the factors associated with the incidence of anemia in pregnant women in the work area of the UPTD Puskesmas Siak Hulu I and III in 2018. The research method uses design cross sectional. The population is pregnant women in the third trimester of 2018. The number of samples is 211. Sampling is done by simple random sampling. Data analysis was carried out by univariate, bivariate and multivariate with multiple logistic regression. The results showed that the variables related to cause and effect on the incidence of anemia in pregnant women in the work area of the Siak Hulu I and III UPTD Puskesmas were adherence to $\mathrm{Fe}$ tablet consumption $\mathrm{OR}=2,74 \quad(95 \% \mathrm{CI}=1.043-7.210)$. Recommended to health workers to conduct KIE activities and promotions for prospective pregnant women, pregnant women and communities in the region.
\end{abstract}

Keywords: Anemia,consumption of Fe tablets, UPTD Puskesmas Siak Hulu I\&III.

\section{ABSTRAK}

Anemia pada kehamilan adalah keadaan dimana kadar Haemoglobin $(\mathrm{Hb})$ pada ibu hamil trimester I dan III < 11 gram \%, sedangkan pada trimester II kadar $\mathrm{Hb}<10,5$ gram \%. Kadar normal Haemoglobin pada ibu hamil $>11$ gram \%. UPTD Puskesmas Siak Hulu I dan III merupakan Puskesmas yang memiliki kasus anemia tertinggi di kabupaten kampar dalam dua tahun berturut - turut yaitu 14,60 \% dan 67,68 \% tahun 2016, sedangkan tahun 2017 adalah 63,63\% dan 85,83\%. Penelitian ini bertujuan untuk mengetahui Faktor-Faktor Yang Berhubungan Dengan Kejadian Anemia Pada Ibu Hamil Diwilayah Kerja UPTD Puskesmas Siak Hulu I dan III Tahun 2018. Metode penelitian menggunakan jenis desaincross sectional. Populasi adalah ibu hamil trimester tiga tahun 2018. Jumlah sampel adalah 211. Pengambilan sampel dilakukan secara simple random sampling. Analisis data dilakukan secara univariat, bivariat dan multivariat dengan regresi logistik ganda. Hasil penelitian menunjukkan variabel yang berhubungan sebab akibat terhadap kejadian anemia pada ibu hamil di wilayah kerja UPTD Puskesmas Siak Hulu I dan III adalah konsumsi tablet Fe dengan OR $=2,74$ (95\% CI=1.043-7.210). Disarankan kepada tenaga kesehatan untuk melakukan kegiatan KIE dan promosi kepada calon ibu hamil, ibu hamil dan masyarakat di wilayah tersebut.

Kata Kunci : Anemia, konsumsi tablet Fe, UPTD Puskesmas Siak Hulu I \& III.

\author{
PENDAHULUAN
}


Anemia pada kehamilan adalah keadaan dimana kadar $\mathrm{Haemoglobin}(\mathrm{Hb})$ pada ibu hamil trimester I dan $\mathrm{III}<11$ gram \%, sedangkan pada trimester II kadar $\mathrm{Hb}<10,5$ gram \% (Saifudin, 2014). Secara global prevalensi anemia pada pada ibu hamil di seluruh dunia adalah sebesar $41,8 \%$. Prevalensi anemia di Asia sebesar 48,2\%, Afrika 57,1\%, Amerika 24,1\%, dan Eropa 25,1\% (WHO, 2011). Prevalensi anemia pada ibu hamil di Indonesia berdasarkan Riset Kesehatan Dasar (Riskesdas) tahun 2013 sebesar 37,1\% (Kemenkes RI, 2013). Di Propinsi Riau sasaran program pembangunan kesehatan adalah menurunkan anemia gizi besi pada ibu hamil menjadi $20 \%$ dan mewujudkan keluarga sadar gizi sebesar 70 \% (Dep. Kes, 2001). Konsumsi tablet besi diintegrasikan dengan pelayanan kunjungan ibu hamil (antenatal care), dimana ibu hamil harus mendapatkan 90 tablet Fe selama masa kehamilan (Dinkes Provinsi Riau, 2014). M enurut laporan A kuntabilitas Kinerja 2016 di Propinsi Riau kejadian Anemia pada ibu hamil masi tinggi yaitu 37,1 \%. Di Kabupaten Kampar angka anemia pada ibu hamil masih memerlukan perhatian khusus, berdasarkan data Dinas Kesehatan Kabupaten Kampar Kejadian anemia ibu hamil pada tahun 2016 sebesar 16,03\%, sedangkan tahun 2017 sebesar 32,59\%. Dari data tersebut terjadi kenaikan yang signifikan melebihi 50\% (Dinkes Kabupaten Kampar, 2017).

Faktor - faktor yang dapat menyebabkan terjadinya anemia kehamilan diantaranya gravid, umur, paritas, tingkat pendidikan, status ekonomi dan kepatuhan konsumsi tablet Fe (Keisnawati, dkk, 2015). Berdasarkan data yang didapat dari 2 wilayah Unit Pelaksana Teknis Daerah (UPTD) puskesmas Siak Hulu I dan III, pada tahun 2016 angka kejadian anemia pada ibu hamil adalah sebesar $14,60 \%$ dan 67,68\%, sedangkan pada tahun 2017 adalah sebesar 63, 63\% dan 85,83\%. Dari data tersebut dapat dilihat terjadi kenaikan kasus dari tahun sebelumnya. Sedangkan wilayah UPTD Puskesmas Siak H ulu III merupakan Puskesmas dengan angka kasus tertinggi dari seluruh puskesmas yang ada di Kabupaten Kampar selama 2 tahun berturut-turut (Dinkes Kabupaten Kampar, 2017). Tujuan Penelitian ini untuk mengetahui faktor-faktor yang berhubungan dengan kejadian anemia di wilayah kerja UPTD Puskesmas Siak Hulu I dan III tahun 2018. M anfaat sosial penelitian ini adalah untuk mendapatkan informasi dalam rangka pencegahan anemia pada ibu hamil di wilayah kerja puskesmas Siak Hulu I dan III Tahun 2018 dan manfaat ilmiah adalah sebagai pengembangan disiplin ilmu kesehatan reproduksi serta mendapatkan informasi untuk penelitian selanjutnya.

\section{METODE PENELITIAN}

Penelitian ini bersifat kuantitatif analitik dengan desain analitik cross sectional Populasi dalam penelitian ini adalah seluruh ibu hamil trimester III yang berada di wilayah puskesmas siak hulu I dan III yang berjumlah 270 orang. Kriteria inklusi yang ditetapkan adalah ibu hamil yang mampu dan mau berkomunikasi untuk diwawancarai dan mengisi kuisioner, ibu hamil yang sudah memasuki kehamilan trimester III dan bertempat tinggal diwilayah UPTD Siak Hulu I dan III. Kriteria Eklusi adalah ibu hamil yang menolak untuk diwawancarai dan mengisi kuisioner, ibu 
hamil yang belum memasuki trimester III dan tidak tinggal diwilayah UPTD Siak Hulu I dan III. Jumlah sampel dalam penelitian ini adalah 211 orang ibu hamil. Pengambilan sampel dilakukan dengan cara simple random sampling.

Pengumpulan data dalam penelitian ini menggunakan data primer dan sekunder. Data primer diperoleh dengan melakukan wawancara dan observasi dengan menggunakan kuisioner, sedangkan data sekunder diperoleh dari buku kohort ibu hamil di wilayah kerja U PTD Puskesmas Siak Hulu I dan III. Variabel - variabel yang digunakan adalah kejadian anemia sebagai variabel dependen, sedangkan variabel independen yaitu konsumsi tablet $\mathrm{Fe}$, pengetahuan, status ekonomi, paritas, umur, dan status gizi. Pengelolaan data meliputi M enyunting data ( Editing), M engkode data ( Coding), M emasukkan data ( Entry), M embersih data ( Cleaning), dan Tabulasi data ( Tabulating). Analisis data dilakukan secara univariat, bivariat dilakukan dengan uju Chi Square dan multivariat dengan menggunakan Regresi Logistik Ganda.

\section{HASIL}

\section{Analisis Univariat}

Hasil univariat menunjukkan bahwa proporsi ibu hamil yang anemia berjumlah 118 orang (55,9\%), ibu hamil yang tidak cukup mengkonsumsi tablet Fe $52,6 \%$, I bu hamil yang memiliki pengetahuan tidak baik 55,0\%, Ibu hamil dengan Status ekonomi rendah $56,4 \%$, Ibu hamil dengan Paritas beresiko anemia 52,1 \%, ibu hamil dengan Pendidikan rendah 55,0\%, I bu hamil dengan U mur beresiko anemia 56,9\%, dan ibu hamil dengan status gizi beresiko 7,1 \%.

\section{Analisis Bivariat}

Hasil analisis bivariat menunjukkan ada 4 variabel independen yang berhubungan signifikan dengan kejadian anemia, yaitu Ibu hamil yang tidak cukup mengkonsumsi tablet $\mathrm{Fe}$ (C.I $>95 \%$; $\mathrm{OR}=1,706-5,270$ ), I bu hamil dengan ekonomi rendah ( C.I $>95 \% ; O R=1,208-3,666$ ), Ibu hamil dengan paritas $\geq 3$ ( C.I $>95 \% ; O R=1,521-4,666$ ), I bu hamil dengan pendidikan rendah ( C.I $>95 \% ; O R=1,608-4,953)$.

\section{Tabel 1}


Hubungan Variabel Independen dengan V ariabel Dependen (Anemia) di Wilayah Kerja UPTD Puskesmas Siak Hulu I Dan III Tahun 2018

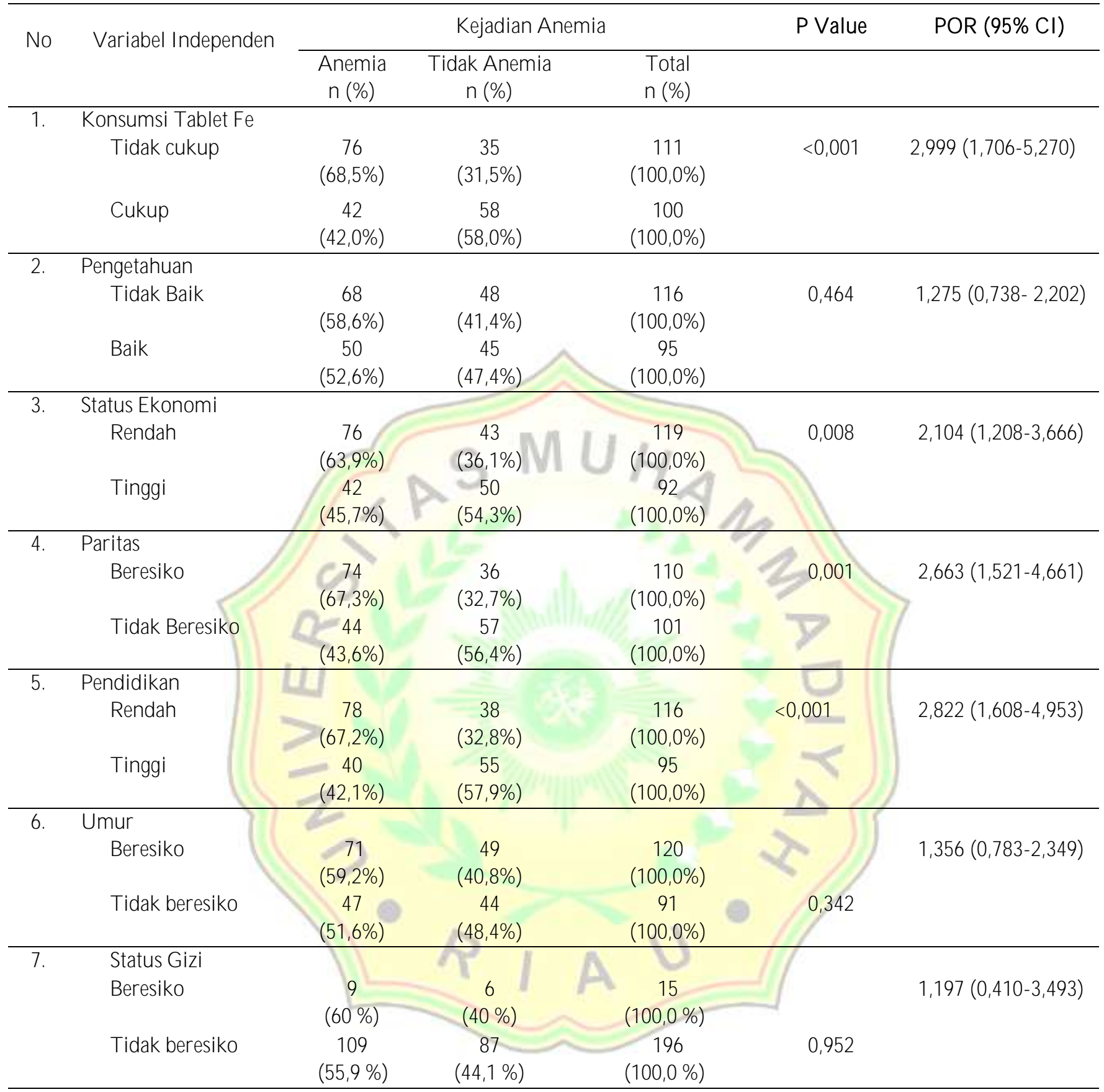

\section{Analisis M ultivariat}

Hasil analisis multivariat dapat disimpulkan bahwa variabel yang berhubungan sebab akibat dengan kejadian anemia adalah konsumsi tablet Fe. Variabel pendidikan dan variatas merupakan variabel counfounding terhadap konsumsi tablet Fe. Hasil Omnibus test of model coeffisient = 0,000 artinya model yang dihasilkan sudah fit/layak digunakan. Nilai N agelkerke R Square $=0,148$ yang berarti konsumsi tablet Fe dan pengetahuan dapat menjelaskan kejadian anemia sebanyak $14,8 \%$ sisanya dapat dijelaskan oleh variabel lain yang belum diteliti. 
Tabel 2

Pemodelan Akhir

\begin{tabular}{clcccc}
\hline No & Variabel Independen & P Value & OR & \multicolumn{2}{c}{$95 \%$ Cl. For EXP (B) } \\
& & & & Lower & Upper \\
\hline 1. & Konsumsi Tablet Fe & 0,041 & 2,742 & 1,043 & 7,210 \\
\hline 2. & Pengetahuan & 0,017 & 0,347 & 0,146 & 0,824 \\
\hline 3. & Paritas & 0,222 & 1,759 & 0,710 & 4,355 \\
\hline 4. & Pendidikan & 0,078 & 1,910 & 0,930 & 3,924 \\
\hline
\end{tabular}

Omnibus test of model coeffisient $=0,000$

Nagelkerke $\mathrm{R}$ Square $=0,148$

\section{PEMBAHASAN}

$\mathrm{H}$ asil penelitian ini menunjukkan adanya rel evansi data karena data yang dikumpulkan, dianalisis dan diinterpretasikan dapat mencapai tujuan khusus dan pembuktian hipotesis. Ada validitas Eksternal dalam arti dapat digeneralisasikan ke populasi yang lebih luas, karena menggunakan desain cross sectional, dan data diambil di wilayah kerja UPTD Puskesmas Siak Hulu I dan III Tahun 2018. Validitas internal terdiri dari random error penelitian ini dengan sampel 211. Bias seleksi dapat dihindari karena pengumpulan data kepada populasi di wilayah kerja UPTD Puskesmas Siak Hulu I dan III Tahun 2018. Bias informasi kemungkinan dapat terjadi dalam pengukuran salah satu variabel independen. Dalam penelitian ini ditemukan variabel confounding yaitu pendidikan dan paritasyang counfounding terhadap variabel konsumsi tablet Fe.

\section{Variabel yang berhubungan dengan kejadian anemia pada ibu hamil}

\section{Konsumsi Tablet Fe}

Dalam penelitian ini konsumsi tablet Fe berhubungan sebab akibat dengan kejadian anemia pada ibu hamil, ibu hamil yang tidak cukup konsumsi tablet Fe lebih beresiko 2,7 kali menderita anemia dibandingkan ibu hamil yang cukup konsumsi tablet Fe. Penelitian ini sejalan dengan penelitian Sugeng Triyani (2015) adanya hubungan yang signifikan antara M engkonsumsi tablet Fe dengan status anemia ibu hamil $(p=0,0001)$. Nilai $O R=5,985$, artinya ibu hamil yang tidak cukup mengkonsumsi tablet Fe mempunyai peluang 5,985 kali terkena anemia dibanding yang cukup. Dalam penelitian ini ditemukan dua variabel confounding terhadap Konsumsi tablet Fe yaitu pendidikan dan paritas. Itu berarti bahwa ibu dengan pendidikan rendah, paritas lebih dari tiga dan tidak cukup mengkonsumsi tablet Fe berpengaruh dengan kejadian anemia pada ibu hamil. Oleh karna itu agar tidak terjadi anemia pada ibu hamil direkomendasikan cukup mengkonsumsi tablet Fe 90 tablet berturut-turut selama kehamilan terutama pada ibu hamil yang berpendidikan rendah dan paritas $>3$. Disarankan pada tenaga kesehatan menunjuk pengawas langsung minum 
90 tablet Fe setiap hari bagi Ibu hamil selama kehamilan dan memberikan tablet Fe pada kunjungan ANC awal trimester dua kehamilan.

\section{Variabel independen yang tidak berhubungan dengan kejadian anemia pada ibu hamil}

\section{Status Ekonomi}

Status ekonomi tidak berhubungan dengan kejadian anemia pada ibu hamil. $\mathrm{H}$ al ini bisa terjadi karna bias informasi responden tidak menyebutkan anggota keluarga lain selain Anak, Ibu, dan Ayah yang ditanggungnya dan kemungkinan pengkategorian untuk variabel status ekonomi belum tepat.

\section{Status Gizi}

Status gizi tidak berhubungan dengan kejadian anemia pada ibu hamil. $\mathrm{H}$ al ini bisa terjadi karena data yang diperoleh homogen.

\section{Umur}

U mur tidak berhubungan dengan kejadian anemia pada ibu hamil. Sebaiknya menggunakan data kontiniu.

\section{KESIM PULAN}

Variabel yang berhubungan sebab akibat dengan kejadian anemia pada ibu hamil adalah Konsumsi tablet Fe, Ibu hamil yang tidak cukup mengkonsumsi tablet Fe beresiko 2,7 kali menderita anemia dibandingkan ibu yang cukup mengkonsumsi tablet fe. ( $\mathrm{Cl} 95 \%=1,043-7$, 210). Dalam penelitian ini ditemukan $V$ ariabel confounding yaitu variable pendidikan dan paritas confounding terhadap konsumsi tablet Fe. Variabel yang tidak berhubungan sebab akibat dengan kejadian anemia pada ibu hamil adalah status ekonomi, status gizi dan umur.

Dalam penelitian ini Ibu hamil direkomendasikan untuk cukup mengkonsumsi tablet Fe 90 tablet berturut-turut selama kehamilan terutama bagi ibu yang paritasnya lebih dari 3. Disarankan kepada petugas kesehatan memberikan promosi kesehatan tentang anemia, akibat serta penanggulangannya dalam kehamilan, Memberikan promosi kesehatan tentang zat gizi/makanan yang mengandung zat besi, Memberikan penyuluhan secara intensif mengenai program pemberian tablet Fe 90 tablet dan akibat dari kekurangan Zat Besi, M elakukan kegiatan KIE dan promosi kepada calon ibu hamil, ibu hamil dan masyarakat di wilayah tersebut, Setiap ibu hamil yang mendapatkan tablet Fe diberikan pengawasan langsung oleh suami/keluarga dalam minum tablet Fe, dan M elakukan monitoring dan evaluasi promosi kesehatan tentang tablet Fe yang sudah dilakukan. Untuk Intervensi Kepada Ibu Hamil dalam hal: Meningkatkan kepatuhan dalam komsumsi tablet Fe agar cukup 90 tablet selama kehamilan, Perlunya pengawasan obat langsung sselama konsumsi tablet Fe oleh suami/keluarga terdekat, dan Mengkonsumsi makanan yang mengandung Zat Besi selama kehamilan. Untuk Peneliti Selanjutnya Perlu dilakukan penelitian lebih lanjut dari responden, dengan menambah variabel lain yang belum diteliti seperti asupan 
gizi, sosial budaya, kebiasaan minum teh, dan pantang makanan, sebaiknya data yang digunakan untuk penelitian berikutnya adalah data kontiniu.

\section{DAFTAR PUSTAKA}

A rikunto. 2010. Prosedur penelitian suatu pendekatan praktek edisi revisi v cetakan 12. Jakarta :PT Rineka Cipta

Badan Pusat Statistik. 2017. Garis Kemiskinan menurut Provinsi 2013 - 2017Jakarta.

Badan Pusat Statistik Provinsi Riau 2017. Garis Kemiskinan Profinsi Riau 2010-2017. Riau.

Diana, Marliza. 2014. Kejadian Anemia Pada Ibu Hamil di Wilayah Kerja Puskesmas Harapan Raya Pekanbaru Tahun 2014.

Depkes RI, 2001. Buku pedoman program kesehatan dan gizi berbasis masyarakat

Kementrian Kesehatan RI. 2013. Buku Ajar Kesehatan Ibu dan Anak. Jakarta: Pusat Pendidikan dan Pelatihan Tenaga Kesehatan.

Keisnawati, Desi Ari Yanti, A pri Sulistianingsi h. 2015. Faktor-faktor terjadinya Anemia Pada Ibu Hamil Primigravida di Wilayah Kerja Puskesmas Tahun 2015. STIKES Peringsewu Lampung.

Kementrian Kesehatan RI. 2013. Profil Kesehatan Indonesia. Jakarta: Kementrian Kesehatan Republik Indonesia.

Lapau, Buchari. 2015. Metodologi Penelitian Kesehatan Metode I/miah Penulisan Skripsi, Tesis dan Disertasi. Jakarta : Pustaka O bor Indonesia.

Profil Dinas Kesehatan Propinsi Riau. 2014.

Profil Dinas Kesehatan Kabupaten Kampar. 2017. Ibu Hamil Yang M endapatkan Target Fe 1 dan Fe 3 M enurut Kecamatan Dan Puskesmas Kabupaten/Kota Kampar.

Profil Dinas Kesehatan Kabupaten Kampar. 2016. Ibu Hamil Yang Mendapatkan Target Fe 1 dan Fe 3 M enurut Kecamatan Dan Puskesmas Kabupaten/Kota Kampar.

Profil UPTD Puskesmas Siak Hulu III. 2017. Rekapitulasi Ibu Hamil dengan Anemia di UPTD Puskesmas Siak Hulu III Tahun 2017.

Profil UPTD Puskesmas Siak Hulu I. 2017. Rekapitulasi Ibu Hamil dengan Anemia di UPTD Puskesmas Siak Hulu I Tahun 2017.

Saifuddin, A. 2014. Pelayanan Kesehatan Material dan Neonatal. Jakarta: JN PKKR Dan Yayasan Bina Pustaka.

Triyani, Sugeng. 2016. Kepatuhan Konsumsi Tablet Fe Dalam M encegah Anemi Gizi Besi Pada I bu Hamil Di Wilayah Puskesmas Kecamatan Jakarta, Pusat. Jurnal IImu Dan Teknologi Kesehatan. Vol. 3. N o. 2, M aret 2016. Hal. 215-229.

World Health Organization, 2011 